\title{
Histomorfometria e indice proliferativo (Ki-67) no carcinoma escamocelular in situ de pregas vocais
}

\author{
Histomorphometry and proliferative index in squamous cell carcinoma in situ of the vocal cords
}

\begin{abstract}
Elisângela Barros Soares Mendonça'; Sandrelli Virginio Vasconcelos Miranda ${ }^{2}$; Adriana Maria da Silva Telles ${ }^{3}$; Paula Abreu-e-Lima ${ }^{4}$; Maria do Carmo Abreu-e-Lima ${ }^{5}$
\end{abstract}

\begin{tabular}{|c|c|}
\hline $\mathbf{u}$ & mo \\
\hline $\begin{array}{l}\text { Laringe } \\
\text { Carcinoma in situ } \\
\text { Prega vocal } \\
\text { Antígeno Ki-67 }\end{array}$ & $\begin{array}{l}\text { Introdução: As displasias da laringe são precursoras do carcinoma escamocelular invasivo e constituem } \\
\text { lesões pouco comuns, pois a maior parte dos casos é detectada como carcinoma invasor. Objetivo: } \\
\text { Caracterizar as displasias acentuadas/carcinoma in situ da prega vocal quanto a área do epitélio, diâmetro } \\
\text { dos núcleos e índice proliferativo, comparando esses dados com os obtidos no epitélio escamoso normal } \\
\text { e de transição. Material e método: Entre as } 1.400 \text { biópsias e peças cirúrgicas de lesões intraepiteliais e } \\
\text { carcinomas invasivos de laringe (1994-2006), foram selecionados cinco casos (0,35\%) pareados com dois } \\
\text { controles de epitélio normal e com a idade; todos foram submetidos a análise morfométrica e imuno- } \\
\text {-histoquímica (Ki-67). Resultados: Comparando-se o epitélio displásico com o normal e de transição } \\
\text { observou-se maior área e diâmetro nuclear no epitélio displásico; não houve diferenças significativas no } \\
\text { diâmetro dos núcleos por camada entre o epitélio displásico e de transição; e o índice proliferativo foi } \\
\text { maior no epitélio displásico com núcleos corados em todas camadas e menor com núcleos limitados } \\
\text { a camada basal e parabasal no epitélio normal e de transição. Conclusão: verifica-se maior área no } \\
\text { epitélio displásico. O diâmetro dos núcleos do epitélio displásico e do de transição são semelhantes, } \\
\text { mas este apresenta núcleos uniformes em toda extensão em contraste com o pleomorfismo do epitélio } \\
\text { displásico. O índice proliferativo (Ki-67) contribui para o diagnóstico diferencial das lesões escamosas } \\
\text { da prega vocal, pois no carcinoma in situ/displasia acentuada observa-se maior número de núcleos } \\
\text { marcados. os quais são vistos em todas as camadas no epitélio. }\end{array}$ \\
\hline
\end{tabular}

abstract

Introduction: Laryngeal dysplasias, precursors of squamous cell carcinomas, are uncommon lesions, inasmuch as most cases are diagnosed as invasive carcinomas. Objective: To characterize severe dysplasia/in situ carcinoma of the vocal cords by comparing the area of involved epithelium, nuclear diameter, and proliferative index with transition and normal squamous epithelia. Material and method: Among 1,400 surgical and biopsy specimens of laryngeal lesions (1994-2006), five cases (0.35\%) were selected and compared according to age with two controls with normal epithelium. Furthermore, all of them were identified and submitted to morphometric and immunohistochemical analysis (Ki-67). Results: After comparing dysplastic with transition and normal squamous epithelia, it was observed an increased nuclear diameter in dysplastic epithelium. Additionally, there was no significant difference in nuclear diameter per layer between dysplastic and transition epithelia. Moreover, the proliferative index was higher in dysplastic epithelium with stained nuclei in all layers and lower in normal and transition epithelia with nuclei concentrated on the basal and parabasal layers. Conclusion: Dysplastic epithelium occupies larger areas. Nuclear diameter is similar in dysplastic and transition epithelia. However, the latter has uniform nuclei, in contrast with pleomorphism in dysplastic epithelium. The proliferative index (Ki-67) contributes to the differential diagnosis of intraepithelial lesions of the vocal cords, inasmuch as in severe dysplasia/in situ carcinoma there is a higher number of stained nuclei, which are seen in all epithelial layers. key words

Larynx

Carcinoma in situ

Vocal cord

Ki-67 antigen

1. Doutoranda do Programa de Saúde da Criança e do Adolescente da Universidade Federal do Pernambuco (UFPE); fonoaudióloga do Núcleo de Atenção ao Servidor da Gerência Regional da Mata Norte, Nazaré da Mata-PE.

2. Mestre em Patologia pela UFPE; fonoaudióloga da Prefeitura Municipal de Maceió e do do Núcleo de Atenção ao Servidor da Gerência Regional de Educação Metropolitana Sul.

3. Doutora em Nutrição pela UFPE; professora Adjunta 1 do Departamento de Patologia da UFPE.

4. Especialista em Anatomia Patológica pelo American Board of Pathology, EUA; patologista do Hospital do Câncer de Pernambuco.

5. Doutora em Patologia pela UFPE; professora associada 2 do Departamento de Patologia da UFPE. 


\section{Introdução}

O câncer de laringe ocorre predominantemente em homens, representando cerca de $25 \%$ dos tumores malignos e $2 \%$ de todas as doenças malignas ${ }^{(3,8)}$, prevalecendo o carcinoma escamoso ${ }^{(3,4,8,11)}$. As lesões precursoras são definidas como alterações do epitélio escamoso, com aumento de risco para carcinoma escamocelular invasivo, e mostram alterações arquiteturais e citológicas que têm sido tradicionalmente agrupadas sob o termo displasia ${ }^{(7)}$.

A classificação da Organização Mundial da Saúde (OMS) subdivide as lesões precursoras em hiperplasia de células escamosas, displasia leve, displasia moderada, displasia severa e carcinoma in situ ${ }^{(7)}$. Na displasia leve, o distúrbio arquitetural e a atipia citológica estão limitados ao terço inferior do epitélio; na moderada, essas alterações se estendem ao terço médio do epitélio; na severa, as alterações estão presentes em mais de dois terços do epitélio. Todavia, a ocorrência de atipia citológica considerável, mesmo limitada a um terço inferior do epitélio, permite graduar a lesão como displasia moderada ou acentuada ${ }^{(7)}$.

No carcinoma in situ, as anormalidades arquiteturais e citológicas estão presentes na espessura completa ou quase completa do epitélio, mas a lesão não ultrapassa a membrana basal. Mitoses atípicas, inclusive na camada superficial, são comuns. A microinvasão é descrita como pequenos brotos epiteliais, que partem da basal e invadem a submucosa. A classificação da OMS não estabelece "ponto de corte" para diferenciar o carcinoma escamocelular microinvasivo do invasivo, tampouco a classificação tumor, linfonodo e metástase (TNM) da União Internacional Contra o Câncer (UICC) ${ }^{(2)}$.

Diagnosticar as displasias da laringe é importante, tanto para prevenir o carcinoma invasivo, quanto para alertar o clínico na detecção de carcinoma invasivo ainda incipiente, já que é sabido que carcinomas invasivos descobertos no prazo de seis meses após o diagnóstico de displasia quase certamente estavam presentes no momento da apresentação inicial(10).

O fumo é um dos principais fatores de risco do câncer de laringe, além do consumo do álcool, e estes têm aumentado progressivamente ${ }^{(1,17,18,21,24)}$. Outros fatores de risco associados ao câncer laríngeo incluem irritação crônica por refluxo gastroesofágico, infecções virais (papilomavírus humano [HPV]), radiação, exposição a carcinógenos químicos, entre outros ${ }^{(16)}$.

As técnicas imuno-histoquímicas, entre outras indicações, contribuem para a graduação e para estabelecer o prognóstico das neoplasias ${ }^{(9,14)}$. O Ki-67 tem sido muito usado como marcador de proliferação e fator prognóstico de neoplasias malignas. O índice proliferativo é usualmente expresso pela porcentagem de núcleos corados, sendo útil no diagnóstico diferencial entre neoplasias benignas e malignas, em situações que a histopatologia não consegue claramente diferenciá-las.

\section{Objetivo}

O objetivo deste artigo é caracterizar a displasia acentuada/carcinoma escamocelular in situ nas pregas vocais em seu aspecto histopatológico, histomorfométrico e índice proliferativo, comparando o epitélio displásico (grupo caso) com o epitélio escamoso normal e de transição dos respectivos controles em relação a área ocupada por cada tipo de epitélio por $\mu \mathrm{m}^{2}$, média do diâmetro dos núcleos das células epiteliais em toda espessura do epitélio, média do diâmetro dos núcleos das células epiteliais nas camadas basal/parabasal, intermediária e superficial, índice proliferativo (densidade dos núcleos corados por área) e localização dos núcleos marcados em relação às camadas do epitélio.

\section{Material e método}

Os casos foram provenientes do arquivo de blocos e preparações histológicas do Departamento de Patologia do Hospital do Câncer de Pernambuco (HCP). No período de janeiro de 1994 a dezembro de 2006, foram analisados 1.400 casos em material de biópsias e peças cirúrgicas de laringe, sendo 1.374 casos de carcinoma escamocelular invasivo de laringe, quatro de carcinoma in situ da laringe, 10 de displasia acentuada da laringe, dois de carcinoma in situ de pregas vocais e 10 de displasia de pregas vocais; estes últimos assim distribuídos: quatro casos de displasia acentuada, quatro de displasia moderada e dois de displasia leve.

Foram aplicados os seguintes critérios de inclusão:

1) Diagnóstico de displasia acentuada e carcinoma escamocelular in situ( ${ }^{(9)}$.

2) Ausência de invasão ao exame clínico ou no acompanhamento posterior, por um período de até um ano após a biopsia inicial.

3) Existência de material emblocado em parafina em quantidade suficiente para a realização de exame imuno-histoquímico e recortes corados em hematoxilina e eosina (HE), quando necessários. 
A seleção resultou em cinco casos correspondentes a cinco pacientes do sexo masculino, todos com diagnóstico histopatológico de displasia acentuada/carcinoma escamocelular in situ das pregas vocais, os quais constituíram o grupo caso.

O grupo-controle consistiu em preparações histológicas de prega vocal obtidas de laringes dissecadas no Serviço de Verificação de Óbitos (SVO) da Secretaria Estadual de Saúde e do Departamento de Patologia da Universidade Federal de Pernambuco (UFPE), a partir de quatro corpos necropsiados que surgiram no período de novembro de 2007 a fevereiro de 2008, com idades de 52, 63 e 78 anos, contemplando os seguintes critérios de inclusão: indivíduo do sexo masculino, não fumante e não etilista, em faixa etária semelhante à do grupo caso, com ausência de lesões macroscópicas da laringe e pregas vocais.

A retirada das laringes foi autorizada pelos familiares após a assinatura do termo de consentimento livre e esclarecido, os quais também forneceram as informações relacionadas com idade e ausência de tabagismo e etilismo.

Das quatro laringes, duas foram utilizadas como grupo-controle, correspondendo a indivíduos com idade de 52 e 78 anos, semelhantes às idades dos pacientes no grupo caso.

O indivíduo número 1 (52 anos) foi utilizado como controle dos casos 1 e 2, de 53 e 55 anos, respectivamente; o indivíduo número 2 (78 anos) foi utilizado como controle para os pacientes 3,4 e 5, de 72, 81 e 85 anos, respectivamente. Foram selecionadas as lâminas histológicas e os respectivos blocos de parafina que continham representação do epitélio escamoso, do epitélio de transição e do epitélio colunar pseudoestratificado ciliado (epitélio do tipo respiratório).

Para análise histomorfométrica, selecionaram-se nas lâminas as áreas cujos diâmetros também foram mensurados. O programa utilizado foi Scion Image Beta 4.0.2 com fotomicrografias, capturadas por microcâmera acoplada ao microscópio óptico Olympus BX41 e transferidas ao computador pelo software de captura de imagem, ATI-Tv Player.

Nos três tipos de epitélio: displásico (grupo caso), epitélio escamoso maduro e de transição (grupo-controle), foram avaliados os seguintes parâmetros:

- média da área $\left(\mu \mathrm{m}^{2}\right)$ ocupada pelo epitélio;

- média do diâmetro dos núcleos na espessura do epitélio como um todo;

- média do diâmetro dos núcleos das células epiteliais por camada ( $1 / 3$ inferior, área intermediária e superficial do epitélio);
- número de núcleos com imunoexpressão do Ki-67 (densidade dos núcleos corados) e localização dos núcleos marcados em relação às camadas do epitélio.

Para mensuração da área do epitélio, utilizou-se fotomicrografias tomadas no aumento de 40x em epitélio plano (Figura 1A e 1B).

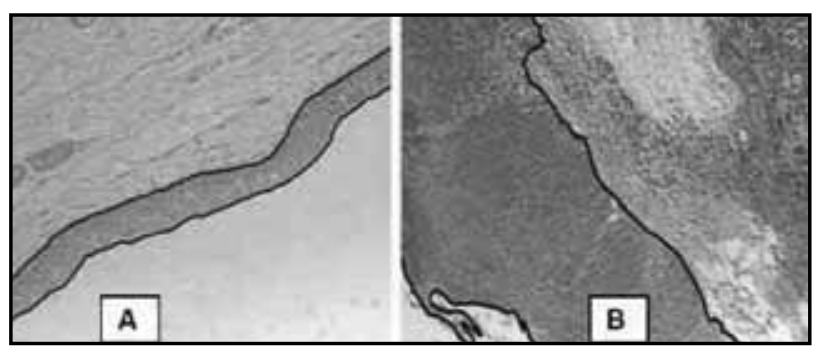

Figura 1 - Mensuração da área (programa Scion Image Beta 4.0.2) A: epitélio escamoso normal; B: epitélio de transição. (HE, 40X). $H E$ : hematoxilina e eosina.

A mensuração do diâmetro foi realizada no maior e no menor eixo dos núcleos em fotomicrografias tomadas no aumento de 400x em 10 núcleos em cada camada (basal/ parabasal, intermediária e superficial). A seleção das áreas para contagem do número de núcleos com imunoexpressão do Ki-67 foi realizada no aumento de $40 x$, sendo a contagem processada no aumento de 400x. O cálculo da densidade de núcleos corados (Ki- 67) foi feito utilizando a seguinte fórmula: $\mathrm{Dnc}=\mathrm{Nnc} / \mathrm{Anc}$, na qual Dnc representa a densidade de núcleos corados; Nnc, o número de núcleos corados; e Anc, a área ocupada pelos núcleos corados.

As reações imuno-histoquímicas foram processadas em laboratório privado de imuno-histoquímica (ImunopatRecife-PE), utilizando-se o anticorpo antiKi-67 (Clone MIB-1, DAKO). Também foram utilizados como controle externo, cortes histológicos de linfonodos normais. Empregaram-se os testes paramétricos de análise de variância (ANOVA) para a comparação entre as médias oriundas de grupos diferentes com relação à média do diâmetro de 10 núcleos por camada em cada caso, totalizando 30 núcleos/caso, que foram pareados aos 10 núcleos por camada correspondentes no epitélio de transição (30 núcleos/controle) e aos 10 núcleos por camada no epitélio escamoso (30 núcleos/controle), seguido do teste de Turkey.

Para comparação das áreas, da média do diâmetro dos núcleos das células epiteliais em toda espessura e da densidade de núcleos corados pelo Ki-67 nos diferentes epitélios, em amostras independentes (uma só variável, 
comparações múltiplas), foi utilizado o teste não paramétrico Kruskal-Wallis e, quando havia significância, seguia-se com o teste de Dunn para área e t- Student Newman-Keuls para densidade. Em todos os casos foi considerado nível de significância $p<0,05$. Toda a análise estatística foi realizada utilizando o programa Bioestati 5.0.

A presente pesquisa foi aprovada pelo Comitê de Ética e Pesquisa do Hospital do Câncer de Pernambuco (protocolo $\left.n^{\circ} 21 / 2007\right)$. As informações obtidas e os nomes dos pacientes foram mantidos em sigilo.

\section{Resultados}

Os casos estudados corresponderam a $0,35 \%$ do total de câncer e displasias de laringe diagnosticados no período de 1994 a 2006 (1.400 casos). O grupo-caso caracterizou-se por cinco amostras de pacientes do sexo masculino, tabagistas e etilistas, com profissões variadas (motorista, vigilante, telegrafista, agricultor e aposentado), com idades de 53, 55, 72,81 e 85 anos, com média de $69,2 \pm 14,67$. O sintoma clínico em todos os casos foi rouquidão. Os pacientes foram submetidos à laringoscopia direta e à biópsia por lesão na prega vocal direita, em três casos, e na prega vocal esquerda, em dois casos. Três pacientes foram tratados apenas com radioterapia e dois, submetidos à radioterapia associada à laringectomia parcial (cordectomia); em dois casos realizou-se a laringectomia total aos 18 e 13 meses após o diagnóstico. $\mathrm{O}$ grupo-controle correspondeu a duas amostras de indivíduos do sexo masculino, não fumantes, não etilistas e aposentados, com idade de 52 e 78 anos, com média de 69,3 $\pm 15,01$. Em ambos, a certidão de óbito registrava como causa de morte infarto agudo do miocárdio (IAM).

O epitélio escamoso displásico das amostras dos cinco casos estudados, caracterizou-se pelo aumento da espessura (Figura 1B) em comparação com o epitélio escamoso normal (Figura 1 A). Notou-se, ainda, hipercelularidade em todos os casos de displasia (Figura 2A), com queratinização ou paraqueratose na superfície (Figura 2B).

Os núcleos eram aumentados e preponderantes em toda espessura do epitélio, com variação de forma e tamanho e hipercromasia (Figura 2B). As mitoses estavam presentes em vários níveis do epitélio (Figura $\mathbf{2 C}$ ).

Já as amostras dos controles apresentavam epitélio escamoso de espessura normal (controle número 1, 52 anos [Figura 3A]), ou delgado e hipotrófico (controle número 1, 52 anos [Figura $\mathbf{3 C}$ ]).



Figura 2 - Displasia acentuada

A: notar núcleos aumentados de volume em toda espessura do epitélio escamoso com paraqueratose; $B$ e C: hipercromasia, variação de tamanho e forma dos núcleos e figura de mitose (seta). Grupo-caso número 1. (HE, 400x).

$H E$ : hematoxilina e eosina.

A maturação estava preservada no controle número 2 (78 anos), isto é, núcleos maiores nas células da camada basal e parabasal e núcleos progressivamente menores com citoplasma acidófilo dominante nas células superficiais (Figura 3A). O epitélio de transição não mostrava diferença aparente na espessura, em relação ao epitélio escamoso maduro, todavia, os núcleos eram preponderantes em toda espessura do epitélio, porém uniformes, sem pleomorfismo e com cromatina delicada. Não foram observadas mitoses.

\section{(Figuras 3C e 3D).}

$\mathrm{Na}$ análise morfométrica dos epitélios, foi observado que as medianas das áreas do epitélio displásico apresentaram diferença significativa em relação ao epitélio escamoso normal e de transição $(p<0,05)$; também se verificou que a mediana das áreas do epitélio de transição foi menor que a do epitélio escamoso normal, todavia, essa diferença não foi significativa. A mediana da área do epitélio displásico foi de 675.567,605 $\mu \mathrm{m}^{2} \pm$ intervalo interquartílico $(\mathrm{IQ})=185.732,13$; a do escamoso maduro, de $108.600,766 \mu \mathrm{m}^{2} \pm \mathrm{IQ}=80.719,9$; e a do de transição, de 69. 248, $666 \mu \mathrm{m}^{2} \pm \mathrm{IQ}=284.66,5$.

Quanto às medianas do diâmetro dos núcleos por epitélio, verificou-se que houve diferença estatística entre as medianas dos diâmetros dos núcleos, tanto entre o epitélio escamoso displásico (mediana $8,55 \mu \mathrm{m}^{2}$, $\mathrm{IQ}=2,10$ ) com o escamoso normal (mediana $6,55 \mu \mathrm{m}^{2}$, $\mathrm{IQ}=1,38)$ quanto entre o escamoso displásico e o escamoso de transição (mediana 7,30 $\mu \mathrm{m}^{2}, \mathrm{IQ}=0,97$ ), além do escamoso normal e o escamoso de transição $(p<0,05)$. Contudo, ao comparar as médias do diâmetro 


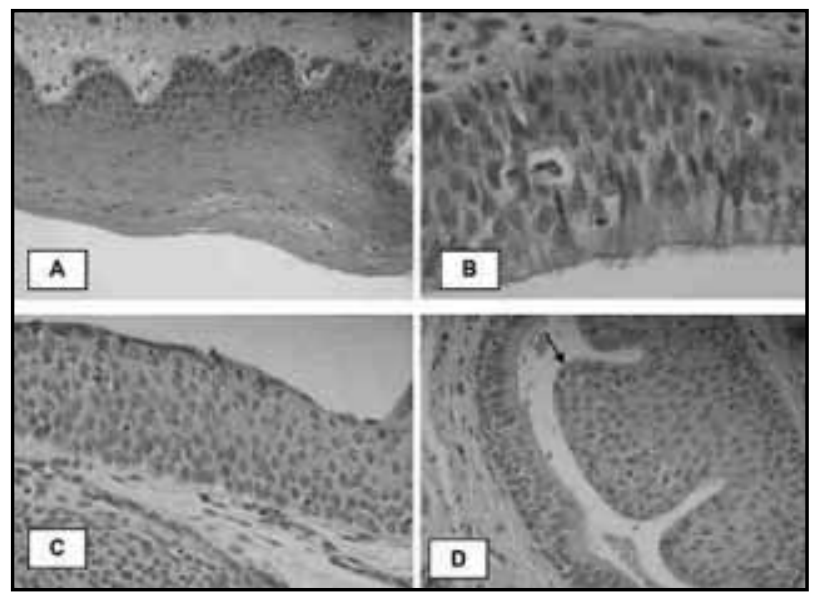

Figura 3 - Epitélio escamoso, pseudoestratificado e epitélio de transição

A: epitélio escamoso da prega vocal com maturação das células epiteliais, núcleos predominantes na camada basal e parabasal e núcleos pequenos nas células mais superficiais. Grupo-controle número 2 (HE, 400x); B: epitélio cilíndrico ciliado, pseudoestratificado (epitélio respiratório). 0 aspecto assemelha-se ao epitélio de transição, porém com epitélio colunar ciliado em superfície. Grupo-controle número 2 (HE, 100x e 400x); C: epitélio de transição. Os núcleos são preponderantes em toda espessura do epitélio, porém, uniformes, de cromatina delicada. Grupo-controle número 1 (HE, 400x); D: glândula mucosa em processo de metaplasia escamosa (seta). Nota-se semelhança do epitélio metaplásico com o de transição. Grupo-controle número 1 (HE, 400x).

$H E$ : hematoxilina e eosina.

dos núcleos por camadas (basal/parabasal, intermediária e superficial) nos diferentes epitélios, observou-se significância apenas entre a média do diâmetro dos núcleos da camada superficial nos epitélios displásico $(8,09 \pm 0,91$ em comparação com o epitélio escamoso normal $(5,7$ $\pm 0,42$ ), com predomínio de núcleos maiores nos casos de displasia acentuada/carcinoma in situ, em comparação com os núcleos da camada superficial do epitélio escamoso normal. Não foi verificada diferença no diâmetro dos núcleos das células epiteliais nas diferentes camadas quando se comparou o epitélio escamoso displásico com o epitélio escamoso de transição. Todavia, no epitélio escamoso normal verificou-se diferença significativa entre o diâmetro do núcleo da camada intermediária (média 7,95 $\mu \mathrm{m}^{2} \pm$ 0,9 ) e da superficial (média 5,71 $\mu \mathrm{m}^{2} \pm 0,42$ ) e entre a camada basal (média $6,01 \mu \mathrm{m}^{2} \pm 0,91$ ) e a intermediária (média 7,95 $\mu \mathrm{m}^{2} \pm 0,9$ ).

Em relação à densidade dos núcleos marcados com Ki-67, verificou-se que o epitélio escamoso displásico mostrava núcleos corados em maior quantidade por área (Figura 4A e 4B), com média de 23,4 núcleos corados no epitélio displásico e dois, tanto no epitélio escamoso normal como no epitélio de transição (Figura 4C e 4D). Essa diferença foi significativa para os três tipos de epitélio.

No epitélio escamoso normal e de transição, predominaram áreas com pouco ou nenhum núcleo corado, não apresentando diferença significativa entre o escamoso comum e o de transição quanto ao número de núcleos corados (Figura 4C e 4D, respectivamente). Os núcleos corados estavam presentes apenas na camada basal/parabasal, tanto no epitélio escamoso normal como no epitélio escamoso de transição (Figura 4C e D), em contraste com a distribuição em todas as camadas no epitélio displásico (Figura 4A e 4B).



Figura 4 - Exame imuno-histoquímico: displasia acentuada

A: aumento da espessura do epitélio com grande número de núcleos corados em toda espessura deste. Grupo-caso número 4 (ki-67, 400x); B: núcleos corados em todos os níveis do epitélio. Grupo-caso número 5 (ki-67, 100x e 400x); C e D: exame imuno-histoquímico - epitélio de transição. Observam-se raros núcleos corados na camada basal e parabasal semelhante à Figura $C$ no epitélio escamoso normal. Grupo-controle número 4 (ki-67, 400x).

\section{Discussão}

A displasia acentuada/carcinoma escamocelular in situ limitado às pregas vocais é pouco comum, particularmente em hospitais públicos, como no deste presente estudo, devido ao baixo percentual $(0,35 \%)$ encontrado no período de 12 anos (1994-2006), refletindo o fato de que a maioria dos pacientes chega ao serviço em estadio avançado da doença. Talvez como consequência disso, verifica-se que a literatura é pobre no que se refere à displasia acentuada/carcinoma in situ da prega vocal e ao número de casos reduzidos, mesmo quando avaliados longos períodos de tempo. Do mesmo modo, não foram encontrados muitos estudos utilizando histomorfometria e/ou avaliando o (Ki-67).

Na rotina do patologista geral, é baixa a prevalência das lesões displásicas da prega vocal, em contraste com o grande número de lesões escamosas intraepiteliais da cérvix uterina. Assim, é comum os patologistas utilizarem 
frequentemente os mesmos critérios usados para graduar as lesões do colo uterino na interpretação das lesões do trato aerodigestivo superior por estarem muito arraigados na sua memória visual.

Embora, de fato, as alterações sejam semelhantes, há algumas diferenças que podem afetar a correta avaliação e o diagnóstico histopatológico dessas lesões no trato aerodigestivo superior. Por isso, é importante a descrição detalhada das displasias da prega vocal e dos aspectos histológicos do epitélio escamoso normal, sobretudo o de transição.

A queratinização e a maturação superficial podem ocorrer nas displasias de laringe e pregas vocais, levando a uma graduação subestimada do grau da displasia na prega vocal, desde que, no colo uterino, queratinização e paraqueratose não sejam frequentes e, quando estas ocorrem, geralmente se associam à maturação superficial e são graduadas como displasia moderada (neoplasia cervical intraepitelial [NIC] 2) ou leve (NIC 1), de acordo com o nível de comprometimento das camadas do epitélio escamoso ${ }^{(6,19)}$.

Embora a classificação da Organização Mundial da Saúde (OMS) 2003 para lesões da cérvix uterina permita o diagnóstico de lesão escamosa de alto grau (NIC 2 ou NIC 3) em lesões com maturação na camada superficial e até intermediária, mas com atipia significativa e mitoses anormais no terço inferior do epitélio, isso não ocorre frequentemente ${ }^{(19)}$. Já na laringe e nas pregas vocais, a qualidade das alterações citológicas parece ser mais valorizada do que o nível do epitélio envolvido, a exemplo de caso descrito ${ }^{(25)}$ diagnosticado como displasia severa queratinizante, cujas alterações limitavam-se às camadas profundas, nas áreas de alongamento das papilas do epitélio escamoso.

Notou-se queratinização no caso número 3, paraqueratose associada a alguma maturação superficial no caso número 1 (Figura 2) e maturação superficial exclusivamente no caso número 5. Apesar da existência da maturação superficial nos casos números 1 e 5, o atipismo significativo nas camadas intermediária e profunda permitiu o diagnóstico de displasia acentuada (Figuras 2B e 2C). Problemas de interpretação também surgem na avaliação do epitélio escamoso de transição ou no escamoso hipotrófico da prega vocal. Dificuldades semelhantes ocorrem no colo uterino, tanto em relação ao epitélio escamoso metaplásico imaturo como na interpretação do epitélio hipotrófico da pós-menopausa; este último, particularmente no exame citopatológico ${ }^{(6,19)}$.

Tanto o epitélio de transição na prega vocal quanto o epitélio metaplásico imaturo do colo uterino podem ser confundidos com epitélio displásico, dado o tamanho aumentado do núcleo em toda espessura do epitélio, sem a maturação progressiva verificada no epitélio escamoso maduro ${ }^{(10)}$. Em ambos os casos, os núcleos são regulares, arredondados ou ovais, relativamente uniformes, sem pleomorfismo, com cromatina delicada e sem hipercromasia (Figura 3C). Do mesmo modo, as figuras de mitose são incomuns, confinadas à camada basal, e nunca anormais no epitélio de transição da prega vocal.

As dificuldades de interpretação do epitélio de transição na prega vocal e do metaplásico imaturo na cérvix uterina são maiores quando esse epitélio estende-se às glândulas mucosas no primeiro caso. Os aspectos de linguetas aprofundadas na submucosa pela substituição do epitélio glandular podem ser interpretados como carcinoma in situ ou como invasão, sobretudo quando não restam remanescentes do epitélio glandular. As características acima citadas de núcleos relativamente uniformes sem pleomorfismo e o contorno bem delimitados das projeções epiteliais excluem microinvasão.

Na prega vocal, o epitélio de transição pode ser visto eventualmente substituindo o epitélio das glândulas mucosas (Figura 3D). O epitélio escamoso hipotrófico também pode causar erros de interpretação. No colo uterino, na pós-menopausa, a deficiência estrogênica leva à redução da espessura do epitélio malpighiano e à falta de maturação; esse fato não acomete somente a camada basal/parabasal|(6,19). Assim, o epitélio escamoso tem aspecto delgado e é formado por células parabasais/ basais, as quais têm núcleos preponderantes. Essas células, ao exame citopatológico, podem ser tomadas como indicativas de NIC pela sua alta relação núcleo-citoplasma. O controle de 78 anos mostrou epitélio escamoso hipotrófico com alguma falha na maturação epitelial. Todavia, erros de interpretação nesse caso não ocorrem em biopsias cirúrgicas, pois o adelgaçamento do epitélio e a uniformidade dos núcleos podem ser verificados, tanto na prega vocal quanto na cérvix uterina. Na histomorfometria ficou evidente que a área de epitélio escamoso displásico é maior que a dos epitélios escamosos (Figura 1). O epitélio escamoso de transição mostrou menor área que o escamoso normal, no entanto, essa característica não foi significativa.

O achado significativo dos núcleos de diâmetros maiores no epitélio escamoso displásico (mediana $8,55 \mu \mathrm{m}^{2}$, $\mathrm{IQ}=2,10$ ) em comparação com o epitélio de transição (mediana $7,30 \mu \mathrm{m}^{2}, \mathrm{IQ}=0,97$ ) e o escamoso normal (mediana $\left.6,55 \mu \mathrm{m}^{2}, \mathrm{IQ}=1,38\right)$ confirma os achados verificados de 
forma subjetiva na avaliação histopatológica. Os núcleos no epitélio de transição (Figura 3C) são maiores do que os do epitélio escamoso normal (Figura $3 \mathrm{~A}$ ) e esse aspecto associado à ausência de diferenças significativas no diâmetro dos núcleos nos diversos níveis de profundidade no epitélio de transição podem levar ao erro de interpretação diagnóstica. Portanto, na análise desse epitélio, a espessura menor e a ausência de pleomorfismo celular e nuclear são os critérios mais importantes para distinção de displasia.

Entre os epitélios escamoso displásico e escamoso de transição, não houve diferenças no diâmetro dos núcleos nas diferentes camadas, pois ambos os núcleos são preponderantes. Logo, a distinção entre o epitélio displásico e o de transição é mais de natureza qualitativa, devido a atipia, pleomorfismo celular e nuclear, hipercromasia etc., expressa no epitélio displásico e ausente no de transição.

O Ki-67 tem sido ainda citado como útil no diagnóstico diferencial de lesões intraepiteliais na cérvix uterina ${ }^{(16)}$. Na laringe, pode também ser útil no diagnóstico das displasias, evitando erros de interpretação, sobretudo pelo aspecto do epitélio de transição da prega vocal com núcleos preponderantes em toda espessura.

Houve diferenças significativas entre a densidade dos núcleos corados pelo Ki-67 quando se comparou o epitélio displásico com o escamoso normal e de transição, pois aquele tinha grande número de núcleos com imunoexpressão do Ki-67, os quais estavam presentes em todos os níveis do epitélio (Figura 4A e 4B). Esses achados estão de acordo com os relatos da literatura que abordam a laringe $\mathrm{e}^{(2,12,20,23)}$ e também com os aspectos verificados na cérvix uterina ${ }^{(13)}$. Na reatividade da imuno-histoquímica para Ki-67, a literatura tem mostrado a relação do maior número de núcleos corados com o grau da displasia e o índice mitótico ${ }^{(15,22) .}$

São poucos os estudos de índice proliferativo em displasias da laringe ${ }^{(2,12,20,23)}$. Em estudo de lesões escamosas da laringe, verificou-se aumento da imunoexpressão do Ki-67 nas displasias, à medida que o grau de atipia aumentava, e considerou-se que o alto índex proliferativo poderia ser indicativo de maior probabilidade de recorrência ou progressão para malignidade nas lesões pré-cancerosas da prega vocal. Todavia, nem sempre é verificada a correlação do índex proliferativo com o grau histológico ou diâmetro tumoral nos carcinomas escamocelulares invasivos ${ }^{(21)}$. Já no estudo de Zidar, por sua vez, encontrou correlação entre o índex proliferativo e o grau histológico do carcinoma escamocelular invasivo ${ }^{(23)}$.
O índex proliferativo pode ser utilizado nas biópsias de lesões displásicas da laringe para seleção de pacientes que vão requerer um follow-up mais cuidadoso. Um estudo de 32 lesões de baixo grau (displasia leve) na laringe, das quais dez progrediram para câncer, encontrou imunomarcação para Ki-67 em mais de 10\% das células displásicas, em 11 (34\%) casos. Destes, 10 (90\%) corresponderam àquelas lesões que evoluíram para carcinoma invasor ${ }^{(12)}$.

Alguns estudos demonstram que o índex proliferativo aumenta de acordo com o grau de atipia encontrado em biopsias de laringe ${ }^{(5,23)}$.

No material do estudo, a imunoexpressão do Ki-67 foi mínima ou ausente, tanto no epitélio escamoso de espessura normal ou hipotrófico como no de transição consistente, com proliferação celular controlada pelos mecanismos normais de crescimento e renovação epitelial (Figura 4C e 4D). Esses dados são semelhantes aos relatados na cérvix uterina, na qual o epitélio escamoso hipotrófico exibe pouca ou nenhuma positividade para $\mathrm{Ki}-67^{(11)}$ e no epitélio metaplásico encontra-se discreta positividade, mas nunca acima de $25 \%$ de núcleos corados ${ }^{(13)}$.

Não se observou aumento do número de núcleos corados quando na comparação do epitélio normal da prega vocal com o de transição. No caso do epitélio de transição, cuja morfometria não demonstrou diferença significativa no diâmetro dos núcleos nas diferentes camadas em comparação com o epitélio escamoso normal, o índex proliferativo foi capaz de excluir displasia, com clareza irrefutável, pois no epitélio de transição o índex proliferativo é muito baixo e limitado às camadas profundas (Figura 4D).

\section{Conclusão}

Verifica-se baixa frequência das displasias da prega vocal, com predomínio do sexo masculino, na faixa etária de 50 a 60 anos, com hábitos de tabagismo e etilismo. $\mathrm{Na}$ comparação entre epitélio escamoso displásico, normal e de transição, quanto aos parâmetros morfométricos e índice proliferativo (Ki-67), observou-se que o epitélio displásico ocupa maior área por $\mu \mathrm{m}^{2}$ do que o epitélio escamoso normal e de transição; a média do diâmetro dos núcleos foi maior no epitélio displásico, seguida do epitélio de transição e do escamoso normal; não há diferença no diâmetro dos núcleos nos diferentes níveis de profundidade entre 0 epitélio escamoso displásico e o escamoso de transição; 0 diâmetro dos núcleos do epitélio escamoso normal é maior 
na camada intermediária e basal do que na superficial; o índex proliferativo é alto no epitélio displásico, com imunomarcação para Ki-67 em todos os níveis do epitélio; o índex proliferativo é baixo no epitélio normal e de transição, com imunoexpressão do Ki-67 limitada à camada basal/ parabasal.

\section{Referências}

1. APRIGLIANO, F.; MELLO, L. F. P. Tratamento cirúrgico do câncer da laringe: análise de 1055 casos. Arq Int Otorrinolaringol, v. 10, n. 1, p. 36-45, 2006.

2. BRASIL. Ministério da Saúde. Secretaria de Atenção à Saúde. Instituto Nacional de Câncer. TNM: classificação de tumores malignos. 6. ed. Rio de Janeiro: INCA, 2004. p. 38-40.

3. CAMPOS, R. J. D. S.; LEITE, I. C. G. Qualidade de vida e voz pós-radioterapia: repercussões para a fonoaudiologia. Rev CEFAC, v. 12, n. 4, p. 671-7, 2010.

4. CISTERNAS, A. V.; TORRENTE, M. A. Radioterapia y el carcinoma verrucoso de laringe. Rev Otorrinolaringol Cir Cabeza Cuello, v. 68, p. 319-22, 2008.

5. COR, A.; GALE, N.; KAMBIC, V. Quantitative pathology of laryngeal epithelial hyperplastic lesions. Acta Otolaryngol, v. 527, p. 57-61, 1997.

6. EDGE S. B.; BYRD, D. R. et al. AJCC cancer staging manual. 7. ed. New York: Springer, 2010.

7. GALE, N.; PILCH, B. Z.; SIDRANSKY, D. et al. Epithelial precursor lesions. In: BARNES, L.; EVESON, J. W.; REICHART, P.; SIDRANSKY, D. Who Classification. World health Organization (OMS): classification of tumors pathology e genetics. Head and neck tumors. Lyon: IARC Press, 2005.

8. Instituto Nacional do Câncer. Tipos de câncer: laringe. Disponível em: <http://www2.inca.gov.br/wps/wcm/ connect/tiposdecancer/site/home/laringe $>$. Acesso em: 12 dez. 2011.

9. JEPSEN, S. A.; CLOSMANN, J. J. The insidious nature and presentation of oral squamous cell carcinoma in the lowrisk population. Gen Dent, v. 56, n. 1, p. 78-82, 2008.

10. MILLS, S. E.; GAFFEY, M. J.; FRIERSON, H. F. Tumors of the upper aerodigestive tract and ear. New York: Armed Forces Institute of Pathology, 2000.

11. MITTAL, K. Utility of proliferation- associated marker MIB-1 in evaluating lesions of the uterine cervix. Adv Anat Pathol, v. 4, n. 4, p. 177-85, 1999.

12. PIGNATARO, L. et al. The predictive value of $\mathrm{p} 53, \mathrm{MDM}-2$, cyclin D1 and Ki67 in the progression from low-grade dysplasia towards carcinoma of the larynx. J Laryngol Otol, v. 112, n. 5, p. 455-9, 1998.

13. RESNICK, M. et al. Viral and histopathologic correlates of MN and MIB-1 expression in cervical intraepithelial neoplasia. Human Pathology, v. 27, n. 3, p. 234-9, 1995.

14. ROCHA, D. A. P.; SOUZA, L. B.; PINTO, L. P. Análise comparativa da proliferação celular entre carcinomas de células escamosas orais HPV-positivos e HPVnegativos. J Bras Patol Med Lab, v. 43, n. 4, p. 269-74, 2007.
15. PUY E SOUZA, R. T. et al. Histomorfometria, apoptose e proliferação celular em neoplasias intraepiteliais do colo uterino. J Bras Patol Med Lab, v. 47, n. 6, p. 625-34, 2011.

16. RODRIGUES, G. F.; LASCIO, T. B. D.; FUJITA, R. Manejo da lesão pré-neoplásica e neoplásica de prega vocal. Acta ORL, v. 25, n. 4, p. 259-62, 2007.

17. SARTOR, S. G. et al. Riscos ocupacionais para o câncer de laringe: um estudo caso-controle. Cad Saúde Pública, v. 23, n. 6, 2007.

18. SHAFEY. O.; ERIKSEN, M.; ROSS, H.; MACKAY, J. The tobacco atlas. 3. ed. Atlanta: American Cancer Society, 2009.

19. TAVASSOLI, F. K.; DEVILEE, P. WHO classification of tumours. Tumours of the breast and female genital organs. Lyon: IARC Press, 2003.

20. URANO, M. et al. An immunohistochemical study of proliferating cell nuclear antigen (PCNA) and MIB-1 in epithelial hyperplasia and dysplasia of the vocal cords. Nippon Jibiinkoka Gakkai Kaiho, v. 99, n. 3, p. 395-401, 1996.

21. VASCONCELOS, S. V. et al. Efeitos do fumo nas dimensões das pregas vocais de idosos. Arq Int Otorrinolaringol, v. 13, n. 1, p. 24-9, 2009.

22. VIEIRA, F. L. D. et al. Avaliação do índice proliferativo pela expressão de Ki-67 em amostras de carcinoma de células escamosas da mucosa bucal e correlação com a graduação histológica. Odont Clin Cient, v. 8, n. 4, p.359-63, 2009.

23. ZIDAR, N. et al. Expression of Ki-67 antigen and proliferative cell nuclear antigen in benign and malignant epithelial lesions of the larynx. J Laryngol Otol, v. 110, n. 5, p. 440-5, 1996.

24. WAGNER, G. A. et al. Alcohol and drug use among university students: gender differences. Rev Bras Psiquiatr, v. 29, n. 2, p. 123-9, 2007.

25. WENIG, B. M. Keratinizing dysplasia of upper aerodigestive tract. Pathology case reviews, v. 13, n. 1, p. 9-16, 2008. 